\title{
Biofilm and planktonic population distribution. Key aspects in carbonaceous anodes for microbial fuel cells.
}

Short title: Biofilm and planktonic population distribution in microbial fuel cells

Sara Mateo, Pablo Cañizares, Manuel Andrés Rodrigo, Francisco Jesus Fernandez-Morales* University of Castilla-La Mancha, ITQUIMA, Chemical Engineering Department, Avenida Camilo José Cela S/N. 13071 Ciudad Real, Spain.

* Corresponding author: Francisco Jesús Fernández Morales

University of Castilla-La Mancha, ITQUIMA, Chemical Engineering Dept., Avda. Camilo José Cela S/N 13071, Ciudad Real, Spain.

Tel: 0034926295300 (ext. 6350), Fax: 0034926295242.

E-mail: fcojesus.fmorales@uclm.es

Orcid iD: 0000-0003-0389-6247 


\section{Abstract}

BACKGROUND: A comparison between different carbon-based anodes used in Microbial Fuel Cells (MFCs) has been carried out. Five different carbonaceous anodes were studied: carbon paper, carbon cloth, carbon foam 30 ppi, carbon foam 80 ppi and carbon felt.

RESULTS: The current density generated was higher for the MFCs with porous anodes compared to the flat ones, exerting up to $14.5 \mathrm{~A} \mathrm{~m}^{-2}$. However, when the superficial surface was higher than $7500 \mathrm{~m}^{2} \mathrm{~m}^{-2}$ the performance did not increase anymore due to microorganisms transport and mass transfer limitations. Regarding to the biochemical performance, a linear relationship between the exerted current density and the coulombic efficiency was found. This relationship indicates a selection of the electrogenic microbial population when the superficial surface increases. From Illumina MiSeq analyses, it was observed that Shewanella population in the biofilm was circa $14 \%$, whilst its population was negligible in the planktonic culture. This population distribution can be explained because of the low growth rate of the Shewanella.

CONCLUSIONS: These results demonstrate that the main driving force of the carbonaceous materials performance lays on the easiness of the biofilm formation and the subsequent population selection, but not on specific electronic properties of the carbon materials.

Keywords: Biofilm, microbial fuel cell, environmental biotechnology, electrochemistry. 


\section{Introduction}

The discovery of electrogenic bacteria led to the development of Microbial Fuel Cells (MFCs). Nowadays, the MFCs stand up as an alternative technology to produce renewable and environmental friendly electricity because it can convert the chemical energy contained in biodegradable substrates into electrical energy ${ }^{1,2}$. During last decades, this technology has been intensively studied with the aim to increase its performance and to get a successful realworld application.

In the literature, it has been described the influence of the main parameters affecting the performance of a MFC. Some of these parameters are the design and configuration of the MFC ${ }^{3,4}$, the external resistance ${ }^{5}$, inoculation ${ }^{6,7}$, carbon source ${ }^{8}$, operational temperature ${ }^{9}$, loading rate $^{1}$ and sludge age ${ }^{10,11}$. Usually, the high performance is linked to high coulombic efficiencies (CE), high surface to volume (S/V) ratio and low internal resistances ${ }^{12,13}$. Many results agree with millilitre-scale MFCs as the ones yielding the best performances ${ }^{14}$ because of its very low internal resistance and its very high $\mathrm{S} / \mathrm{V}$ ratio. In the literature, a volume density of $500 \mathrm{~W} \mathrm{~m}^{-3}$ has been achieved by a $1.2 \mathrm{~cm}^{3} \mathrm{MFC}$ with a high surface area-volume ratio to enhance the proton diffusion and $1010 \mathrm{~W} \mathrm{~m}^{-3}$ got by an air-breathing MFC of $2.5 \mathrm{~cm}^{3}{ }^{15}$. Due to its small dimensions, this technology can be used as portable power supplies, especially when they are connected to each other ${ }^{16}$. Stacking miniaturized MFCs can provide greater power and would guarantee high CE, keeping its small electrode areas ${ }^{17}$.

In order to optimize the size of the MFC, it is crucial to consider the characteristics of the anodic surface because it plays a significant role in the initial adhesion, colonization and formation of electrogenic biofilm as well as in the electron transference ${ }^{18}$.

The anode must be characterized by its biocompatibility, large surface roughness, high electrical conductivity and low resistance, chemical stability, good mechanical strength and toughness, etc. ${ }^{19}$. Moreover, good properties as biomass carrier and efficient electron transfer 
between the bacteria and the electrode surface must be ensured to make true the possibility of real-applications for this technology ${ }^{19}$.

Nowadays, due to its relatively low cost, the carbon based materials are widely used ${ }^{20}$. In the literature, it has been described the use of carbon electrodes as anodic and cathodic electrodes, obtaining, in general, good results ${ }^{19}$. Carbon materials fulfils most of the properties required for anodic electrodes. However, its final performance depends on the form of the carbonaceous material used. Regarding to the carbon form used, it must be highlighted that, on one hand, low resistance can be achieved by reducing the distance between anode and cathode, which can be more easily reached working with flat materials such as carbon paper and carbon cloth. On the other hand, working with porous carbon materials, microorganisms can easily growth on the electrode due to its high porosity and roughness, making easier the biofilm formation.

The specific properties of each carbonaceous materials are related to its electronical configuration, mechanical properties and biocompatibility, porosity, etc. Because of that, it is interesting not only to determine their performance, but also to identify the reasons why the performance is enhanced, with the aim to determine the most adequate material for MFC. In general, carbon-based electrodes as foam and felt are widely used as electrode materials, exhibiting significant advantages over the conventional carbon paper and carbon cloth electrodes. The main advantages of the carbon cloth is its flexibility and porosity being its main drawback the high economical cost when it is compared to other carbonaceous materials ${ }^{21}$. The carbon paper is also flexible, but present lower porosity when it is compared to carbon cloth. Opposite to carbon paper and carbon cloth, carbon foams are much thicker and have more external surface for bacterial fixation ${ }^{22}$. Carbon foam and carbon felt electrodes have not been widely used in conventional MFC. Carbon foam has been used as anode in soil and marine MFC ${ }^{23}$. Despite being very promising, carbon felt has been even less used than carbon foam although it have shown good stability and robustness ${ }^{24}$. In the 
literature, most MFC studies comparing carbonaceous materials focused on volume or membrane area basis, resulting in difficulties in quantitative comparison among the different materials ${ }^{19}$. Because of that, in this work the comparison is based on the superficial surface area.

In this context, the aim of this paper is to study the performance of an air-breathing MFC configured with different carbonaceous materials as anodic electrodes with the aim to identify the driving forces that support their behaviour. To do that, five different carbonaceous electrodes (carbon paper, carbon cloth, carbon foam 30 ppi, carbon foam 80 ppi and carbon felt) were compared, paying attention to both the electrochemical and biochemical performances. 


\section{Methods and materials.}

\subsection{Experimental set-up}

In order to avoid the influence of external factors when comparing the experimental results, all the experiments were carried out simultaneously, inoculated with the same sludge and operated under the same operational conditions. The experimental set-up consisted of several airbreathing MFCs made of methacrylate, being the cathodic chamber exposed to the atmosphere for the operational simplicity and cost-effectiveness ${ }^{1}$. A scheme of the MFC used is presented in Figure 1.

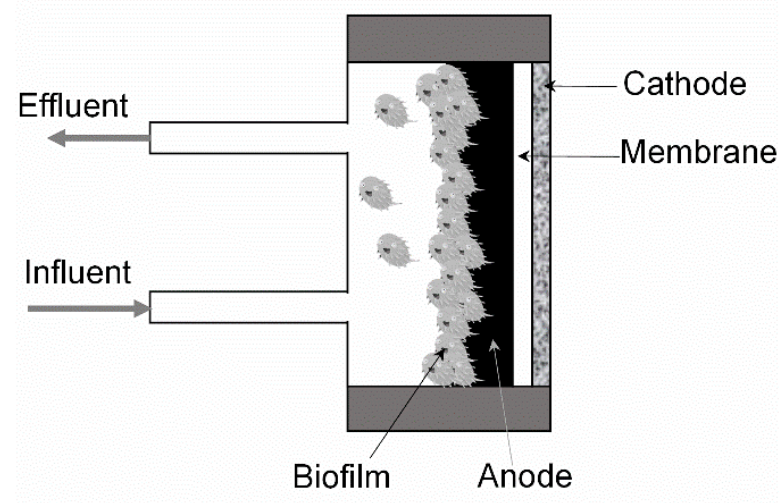

Figure 1. Schematic view of the MFC used in this work.

The cathodic electrodes were air-breathing ones based on Toray carbon papers TGPH-120 (ETEK, USA) with a Teflon content of $10 \%$ to enhance its mechanical properties. Moreover, in the cathode, a catalytic layer with $0.5 \mathrm{mg} \mathrm{Pt} \mathrm{cm} \mathrm{c}^{-2}$ loading was deposited onto a microporous layer to enhance the cathodic catalytic properties ${ }^{6}$. In the literature, the performance of these air-breathing cathodes have been evaluated ${ }^{2}$. From these evaluation tests, it was shown that in all the cases the anodic reaction acts as the limiting process of the whole MFC performance during both the start-up stage and the steady state operation. Additionally, in the literature it 
has also been stated that, when operating with similar air-breathing MFC, the cathodic reaction does not control the MFC performance at the operational conditions defined in this work ${ }^{25}$. Anode and cathode were separated by a Nafion exchange proton membrane (DuPont ${ }^{\mathrm{TM}}$ Nafion PFSA Membrane). Regarding to the anodic electrode materials, a total of five different carbonaceous anodic materials were studied. These five anodic carbonaceous anodes were made of carbon paper (CP), carbon cloth (CC), carbon foam of porosity of 30 ppi (CF30ppi), carbon foam of a porosity of 80 ppi (CF80ppi) and carbon felt (CF). The specific surfaces areas of these materials were $350,1950,3500,5200$ and $17700 \mathrm{~m}^{2} \mathrm{~m}^{-2}$ for the $\mathrm{CP}, \mathrm{CC}, \mathrm{CF} 30$ ppi, CF80ppi and CF electrodes respectively. At this point, it is important to highlight that circular, clean, brand new, anodic and cathodic electrodes, with a diameter of $1.05 \mathrm{~cm}$, were used. The electrical circuit and the electrodes were connected by means of tin wire and an external resistance of $120 \Omega$. The anodic chamber had a total volume of $0.697 \mathrm{~cm}^{3}$ and was connected to an auxiliary tank of $115 \mathrm{~cm}^{3}$. In order to reduce as much as possible the internal resistance, the cathodic electrode and the membrane were assembled by a hot-pressure process and anodic electrode was placed as close as possible to the membrane ${ }^{25}$. For the sake of reproducibility the experiments were carried out in duplicate.

\subsection{Anodes characterization}

In order to characterize the electrode morphology and the biofilm grown over the electrode (REF DIOS), scanning electron microscopy (SEM) images were obtained before and after the experiments by using a FEI QUANTA 250 and the procedure described in the literature ${ }^{26}$. To enhance the accuracy of the images, the samples were pre-treated. The pretreatment consisted on rinsing the electrodes with phosphate buffered saline (PBS), then the microbes were fixed using a solution of $4 \%$ glutaraldehyde and $4 \%$ formaldehyde for $10 \mathrm{~h}$. After that, samples were rinsed three times in PBS (pH 7.0) and once in deionized water. Samples were subjected to a 
graded series of ethanol solutions for dehydration. Finally, the samples were dried by using synthetic air at room temperature ${ }^{26}$.

\subsection{Synthetic wastewater}

In all the MFC the same synthetic wastewater was fed. All chemicals used to synthetize the wastewater were of analytical grade, using as diluent Mili-Q water. The synthetic wastewater used as feedstock consist of $16.10 \mathrm{~g} \mathrm{~L}^{-1}$ of sodium acetate as the sole carbon source and trace minerals: $2.77 \mathrm{~g} \mathrm{~L}^{-1}$ of sodium carbonate, $1.85 \mathrm{~g} \mathrm{~L}^{-1}$ of ammonium sulphate, $1.11 \mathrm{~g} \mathrm{~L}^{-1}$ of potassium dihydrogen phosphate, $0.92 \mathrm{~g} \mathrm{~L}^{-1}$ of hexahydrate magnesium chloride, $1.25 \mathrm{~g} \mathrm{~L}^{-1}$ of calcium chloride and $0.07 \mathrm{~g} \mathrm{~L}^{-1}$ of ferric ammonium sulphate.

\subsection{Inoculation and operational conditions}

MFCs were inoculated with bacteria from an ongoing MFC ${ }^{11}$. This sludge was subjected to an acclimatization process similar to the one previously described in the literature ${ }^{11}$. In order to colonize the electrode, the auxiliary tank was seed with the bacterial inoculum and recirculated to the anodic chamber of the MFC during the first day. The second day, a $50 \%$ of the auxiliary tank volume was replaced by new inoculum and was left in recirculation mode during another day. Then, the system operated in a fed-batch mode by removing $46 \mathrm{ml}$ of the auxiliary tank volume and replacing it with fresh wastewater in a daily basis. MFCs were operated at room temperature and wastewater was pumped into the anodic chamber at a flow rate of $3 \mathrm{ml} \mathrm{min}{ }^{-1}$ by a multichannel Heidolph (PD-5206 Peristaltic Dosing Dispensing Pump Drive).

\subsection{Chemical and electrochemical analyses}

Conductivity and $\mathrm{pH}$ were measured using a GLP22 Crison $\mathrm{pH}-$ meter. The COD removal was measured according to Standard Methods ${ }^{27}$. Regarding the electrical measurements, the output current density was followed by registering the voltage exerted continuously with a Multimeter Keithley 2000 and the electrochemical characterization was carried out periodically by an 
AUTOLAB PGSTAT30. Polarization curves were recorded with an Autolab PGSTAT 30 potentiostat/galvanostat (Ecochemie, The Netherlands) at a scan rate of $1 \mathrm{mV} \mathrm{s}^{-1}$ and a step potential of $1 \mathrm{mV}^{28}$.

\subsection{Microbial Community analyses}

Samples were collected from biofilm and planktonic culture. A total volume of $5 \mathrm{~mL}$ was centrifuged at $5630 \mathrm{~g}$ during 10 minutes in order to obtain the biomass pellet. For the extraction of the genomic DNA (gDNA) from the biomass pellet, $1 \mathrm{~mL}$ of each stored sample was used. Concentration and purity of the gDNA samples were determined by measuring absorbance at three different wavelengths: 230, 260 and $280 \mathrm{~nm}$. DNA content was measured in a Qubit 3.0 fluorometer (Life Technologies) before libraries preparation. Preparation of 16S rRNA gene libraries was performed from $0.2 \mathrm{ng} / \mu \mathrm{L}$ of gDNA samples. The variable region $\mathrm{v} 4$ of bacterial 16S rRNA were amplified using universal primers $515 \mathrm{~F}$ and $806 \mathrm{R}^{29}$. The Polymerase Chain Reaction conditions were as follows: 30 seconds at $95^{\circ} \mathrm{C}$ for the denaturing stage, followed by 28 cycles of annealing stage, at 95,55 and $72^{\circ} \mathrm{C}$ during 30 seconds; and a final elongation stage at $72{ }^{\circ} \mathrm{C}$ during 5 minutes. Resulting libraries of $16 \mathrm{~S}$ amplicons were subsequently multiplexed and sequenced.

The raw data obtained from the Illumina sequencing stage was sequentially processed. The prinseq-pl algorithm ${ }^{30}$ was applied at the trimming stage. The trimmed paired-end reads were joined with default parameters of fastq-join ${ }^{31}$, chimeras were excluded after the application of the tool $\mathrm{UCHIME}^{32}$. Taxonomic assignment was carried out up to genus level, applying a confidence threshold of 0.8 , in the Ribosomal Database Project's Classifier tool ${ }^{33}$. Population analysis results were obtained by using the statistical computing software R. 


\section{Results and discussion}

\subsection{Performance evaluation in MFC}

Figure 2 shows the evolution of the exerted current density of the five MFC tested, which differs only in the carbon anodes used.

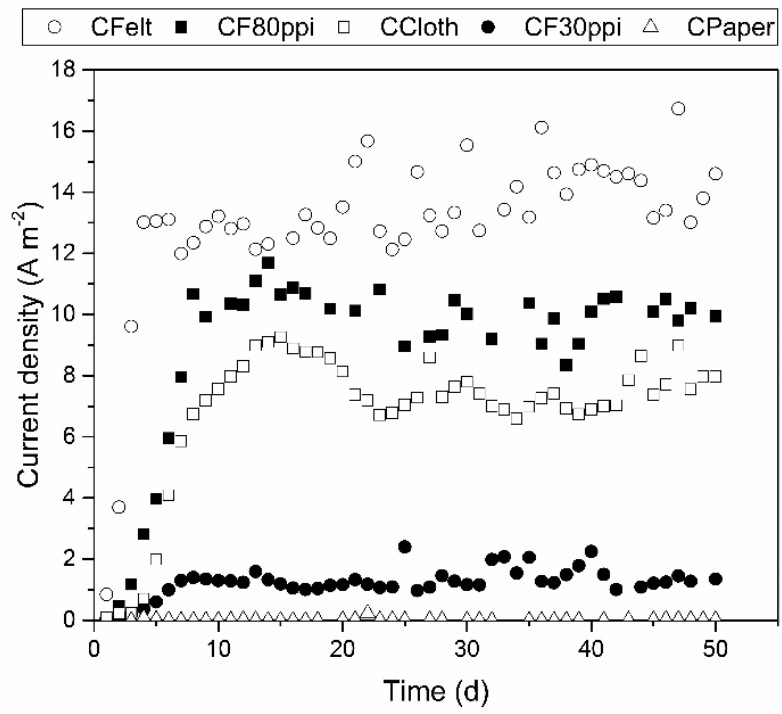

Figure 2. Evolution of the current density exerted by the MFCs with the time.

In most of the cases, an average of about 20 days was required to reach the steady state. Furthermore, materials with high porosity showed a quickly linear increase, whereas flat materials, as the carbon cloth, showed an exponential trend. This can be explained by the main colonization process, entrapment in the case of porous materials and growth over the surface in the case of the flat materials. Regarding to the output current, once the MFCs achieved the steady state, they were operated for one month.

As can be seen in Figure 2, the worst performance was obtained when operating with $\mathrm{CP}$, a similar result to the reported in the literature ${ }^{19}$. On one hand, the low thickness enhances its efficiency in the electron transport. However, on the other hand, CP is very thin, slightly rigid and fragile, presenting a relatively smooth surface. This flat geometry worsens the biofilm 
attachment on the CP anode ${ }^{34}$. The CF30ppi, CC and CF80ppi, more porous carbonaceous materials than the $\mathrm{CP}$, produced current densities of $1.54,6.8$ and $9.8 \mathrm{~A} \mathrm{~m}^{-2}$ respectively. These materials are more flexible and much more porous than $\mathrm{CP}$, allowing to a larger surface for bacterial attachment and facilitating the microorganisms' entrapment in the pores. It must be highlighted the low performance of the CF30ppi, when it is compared with the CC and the CF80ppi. When comparing the CF30ppi with the CC, the low performance of the CF30ppi could be explained because, although carbon foams are much thicker and presents a porous structure, its reticulation reduced the external surface for the bacteria attachment. Moreover the very high pore size favours the entrapment of dyed microorganisms that could clog the pores limiting the mass transfer and therefore the microbial growth ${ }^{19,35}$. The lower performance of the CF30ppi versus the CF80ppi could be explained due to its thin latticework and very high pore size, $0.8 \mathrm{~mm}$, when it is compared with CF80ppi which presents a pore size of $0.3 \mathrm{~mm}$. This combination reduced the available surface for the biofilm attachment and therefore reduced the direct electron transference to the electrode. Finally, the highest current density, 14.5 $\mathrm{A} \mathrm{m}^{-2}$, was obtained when operating with $\mathrm{CF}$.

At this point, it is very interesting to evaluate the total electrons transferred from the substrate to the anode once the steady-state was reached and the CE, see Figure 3a. The CE can be easily determined in the fed-batch operational mode by the integration over the time of the exerted current ${ }^{36}$. 
A)

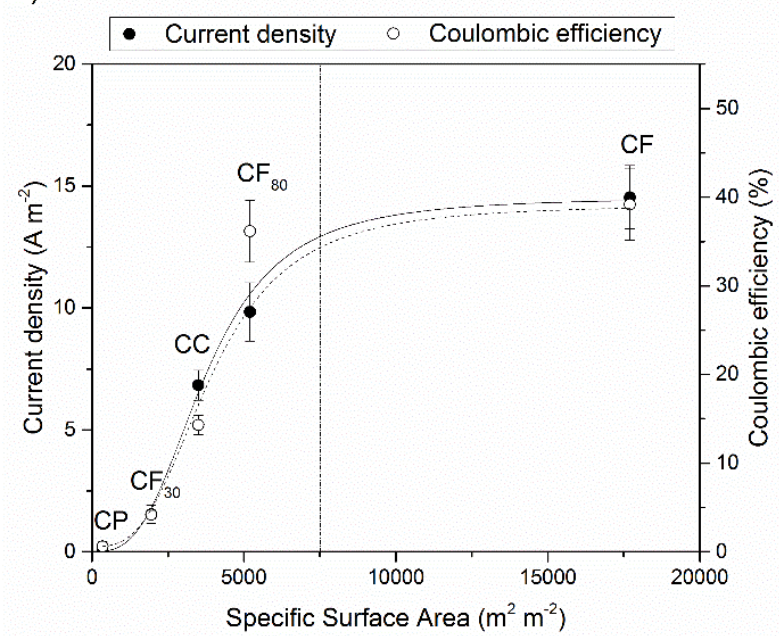

B)

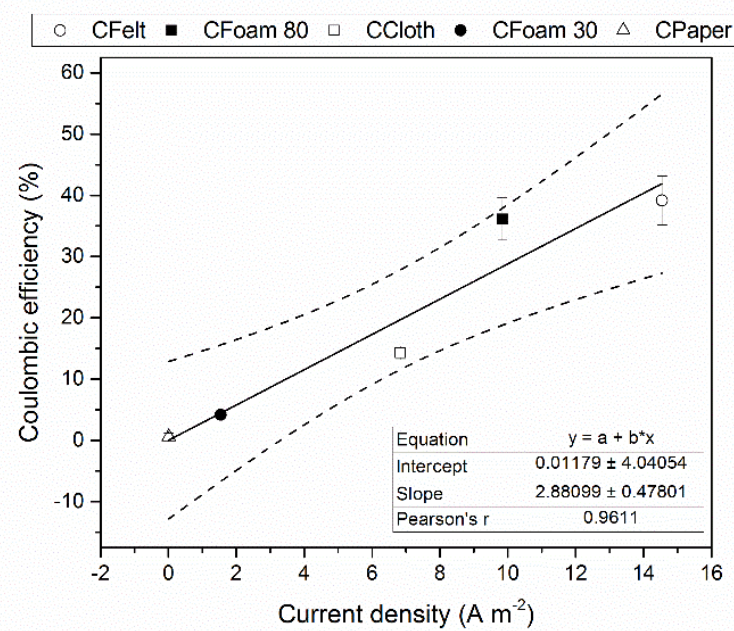

Figure 3. Performance of the carbon materials. A) Current density B) Relationship between CE and current density. Dashed lines corresponds to the $95 \%$ confidence interval.

In Figure 3a, it can be observed that materials presenting the highest superficial surfaces got the best performances. These materials are the porous carbon forms, whose better performance could be explained because of its easier bacterial entrapment and attachment. Higher specific surface areas lead to greater biofilms, which means more direct electron transfer due to the physical contact with the anode ${ }^{37-39}$. The increase followed a sigmoidal trend, ranging the more stepped stage within $2500-5000 \mathrm{~m}^{2} \mathrm{~m}^{-2}$ of superficial surface. The current density clearly changed when shifting from $\mathrm{CP}$ to $\mathrm{CF} 30$ ppi. This can be explained because of the combination of a porous surface and thin latticework, which allow to a low available surface to the electrochemical processes. When the superficial surface of the material further increased, the exerted current density followed the same rising trend. However, when operating with the material presenting the highest superficial surface, $\mathrm{CF}$, the current density exerted was not proportional to the superficial surface. This behaviour could be explained because of the filamentous structure of the $\mathrm{CF}$, that offers a very high external surface, but at the same time could limit the substrate and products mass transfer within the porous of the material. From 
these results, it can be concluded that superficial surface areas higher than $7500 \mathrm{~m}^{2} \mathrm{~m}^{-2}$ does not add any significant increase in the current density.

Regarding to the CE, it can be clearly seen how high superficial surfaces of the anodic materials results in great $\mathrm{CE}$ (36.2\% for CF80ppi and $39.2 \%$ for $\mathrm{CF}$ ), while materials characterized by its plain geometry reach significantly lower efficiencies, such as the $\mathrm{CC}$ achieving a $\mathrm{CE}$ of about $14 \%$.

From these results, the steady-state current density exerted by each carbonaceous material and its CE was correlated with the surface area (Figure 3b). A linear relationship between both variables can be clearly observed. The linear relationship suggests that the increase in the current density is directly related to the development of an enriched electrogenic culture when the MFC is operated with porous electrodes. According to this evidence, the biofilm should be characterized by higher electrogenic population than the planktonic ones.

\subsection{Microbial community structure}

In order to analyse the microbial population in the cultures, Illumina MiSeq technique was used to characterize planktonic and biofilm samples ${ }^{40}$. Attending to the phylum, a significant presence of Proteobacteria was observed, about $84 \%$ in the biofilm and $88 \%$ in the planktonic culture. According to the genus, the prevailing specie in the biofilm were the Acinetobacter (36.6\%) and Pseudomonas (14.8\%), whereas the most abundant in the planktonic culture was

Arcobacter (43.9\%), Acinetobacter (20.7\%) and Pseudomonas (12.0\%). It is important to highlight the significant presence, about a $14 \%$, of Shewanella in the biofilm. However, Shewanella was not detected in the planktonic culture.

These results demonstrated that the electrogenic cultures were mainly located on the biofilm electrode. This could be explained because the biofilm structures allow the growth of slow growing microorganisms, whereas the dilution rate caused by the fed-batch operation washed- 
out the slow growing microorganisms from the liquid bulk. For the sake of clarity, the maximum specific growth rates $(\mu)$ of conventional anaerobic microorganism and of electrogenic microorganisms were compared. This information is presented in Table 1.

Table 1. Maximum specific growth rate of different microbial populations.

\begin{tabular}{lc}
\hline \multicolumn{1}{c}{ Microbial Population } & $\boldsymbol{\mu}\left(\mathbf{h}^{-1}\right)$ \\
\hline Non Electrogenic Microorganisms & \\
\hline Facultative microorganisms $^{41}$ & $0.160-0.048$ \\
\hline Clostridium populeti $^{42}$ & 0.16 \\
\hline Anaerobic Aeromonas hydrophila $^{43}$ & 0.15 \\
\hline Electrogenic Microorganisms $^{43}$ & \\
\hline Clostridium butyricum $^{44}$ & $0.11-0.07$ \\
\hline Shewanella oneidensis $^{45}$ & $0.085-0.04$ \\
\hline Rhodoferax ferrireducens $^{46}$ & $<0.04$ \\
\hline Geobacter sulfurreducens $^{47}$ & 0.037 \\
\hline
\end{tabular}

From Table 1, it can be seen that the electrogenic microorganisms grow slower than other kinds of microorganisms contained in MFC cultures. This fact, combined with feed-batch operation of the MFC, means that the slow growth rate microorganisms, in this case the electrogenic ones, were easily removed from the planktonic culture. In this scenario, only the biofilm structure allowed to the development of the slow growing electrogenic microorganisms.

\subsection{Electrochemical and SEM analyses}

The characterization of the MFCs requires additional electrochemical measurements. For this reason, polarization curves were carried out on a weekly basis. For the sake of clarity, only curves during the start-up and once the steady-state was reached are shown in Figure 4. 

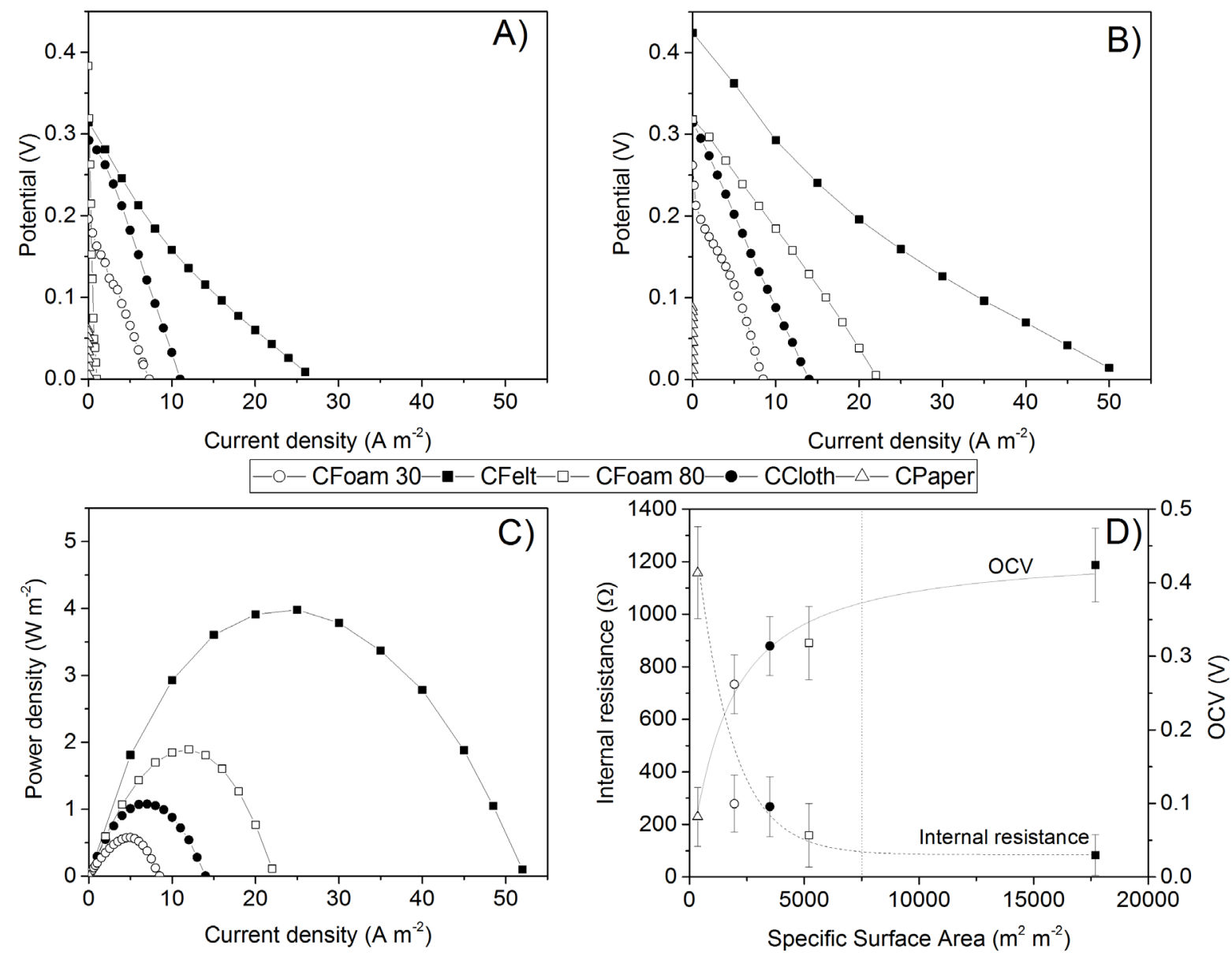

Figure 4. A) Polarization curves in the start-up B) Polarization curves in the steady-state C)

Power curves in the steady-state D) Internal resistance and OCV in the steady-state.

As can be seen when comparing Figures $4 a$ and $4 b$, the time of operation smoothed the slope of the polarization curves. Once reached the steady-state, higher current densities were achieved in all the cases. Anyway, it must be highlighted the case of the CF80ppi, which increases from $0.94 \mathrm{~A} \mathrm{~m}^{-2}$ to $22 \mathrm{~A} \mathrm{~m}^{-2}$ and the case of the $\mathrm{CF}$, which increases from about 27 A m ${ }^{-2}$ until $52 \mathrm{~A} \mathrm{~m}^{-2}$. As it can be seen from the polarization curves, during the start-up, voltage drop was mainly governed by the internal resistance of the electrode, except in the cases of CF and $\mathrm{CC}$, and by transport limitations whose origin could be found in the penetration of bacteria into the pores and mass transfer limitations. The diffusion and transfer problems lose significance once the bacteria started to grow up and activate the mechanisms of electron 
transfer, which can be clearly perceived in the devices by the reduction of the slope in the polarization curves as time goes by. Additionally, there were no significant limitations due to activation losses and/or reaction kinetics. This could be explained by the source of the inoculum, an electrogenic seed taken from an ongoing MFC ${ }^{11}$. In this sense, the only exception was $\mathrm{CP}$, which can be explained by the difficult adherence of the microorganisms to this material because of its smooth morphology.

Regarding to performance of the carbonaceous materials, maximum power density was reached by $\mathrm{CF}$, see Figure 4c, revealing the superb performance of this material achieving $3.99 \mathrm{~W} \mathrm{~m}^{-2}$ during the steady-state, followed by the CF80ppi with $1.89 \mathrm{~W} \mathrm{~m}^{-2}$ and by the CC with $1.08 \mathrm{~W}$ $\mathrm{m}^{-2}$. All these values are much higher than the one obtained when operating with CP $0.022 \mathrm{~W}$ $\mathrm{m}^{-2}$

From the polarization curves obtained once the systems reached the steady-state, the open circuit voltage (OCV) and internal resistance were calculated, see Figure $4 \mathrm{~d}$. Both of them, the internal resistance and the OCV of the carbon materials, presented an exponential decrease and increase respectively. These behaviours could also be explained by the materials geometry. The higher the superficial surface, the higher biofilm formation and therefore the higher the electron transference. From these results, it can be clearly seen that the porous materials outcompete the plain geometry ones but the increase in the performance is not linear, presenting a plateau when the superficial surfaces is higher than $7500 \mathrm{~m}^{2} \mathrm{~m}^{-2}$. All the systems presented their best OCV values during the steady-state as the electrogenic activity keeps constant: 0.082 V for CP, $0.262 \mathrm{~V}$ for C30ppi; $0.314 \mathrm{~V}$ for CC; $0.318 \mathrm{~V}$ for CF80ppi and 0.424 V for CF. From these results, it can be assumed that higher superficial surfaces of carbon-based materials, leads to higher OCV values. During the start-up, as it was commented previously, the principal limitation consists of the internal resistance. At this point, it is worth to highlight that the internal resistance decreased with the operation time in all the cases. Although the plain forms 
are known to produce lower values of internal resistance, because most of its surface is very close to the cathode, its morphology makes more difficult the biofilm colonization and forces the growth of superimposed biofilm layers on the electrode surface leading to a less efficient biofilm and increasing the internal resistance. This fact can be observed in Figure 4d, where the higher value of internal resistance corresponded to $\mathrm{CP}, 1158 \Omega$ during the steady state, which can be the cause of the negligible current density exerted. It is interesting to emphasize that the best values of OCV corresponded to CF $(0.424 \mathrm{~V})$ agreeing with the lowest values of internal resistance of $82.6 \Omega$. In conclusion, the conductivity of the anode rises with the increase of specific area, being the specific area more relevant.

In order to verify the biofilm growth, SEM images of the electrode were took before and after the experiments. In Figure 5, left SEM images correspond to the raw electrode material and the right one to the colonized anode. As can be seen in these pictures, there was a higher biofilm growth in the electrodes presenting higher superficial surfaces. The CF, a fibre fabric much thicker than the other carbon forms, presented a significant higher superficial surface. However, present a loose texture which on one hand favours the bacterial adhesion and on the other hand limits the cellular transport and mass transference to its inner surface. In most of the cases, increasing the superficial surface facilitates the electron transference. However, it is not true when the pore size is too small for bacterial colonization. In the case of the carbon felt the loose fibres create too small pore size making impossible the cellular transport to the inner surface. 


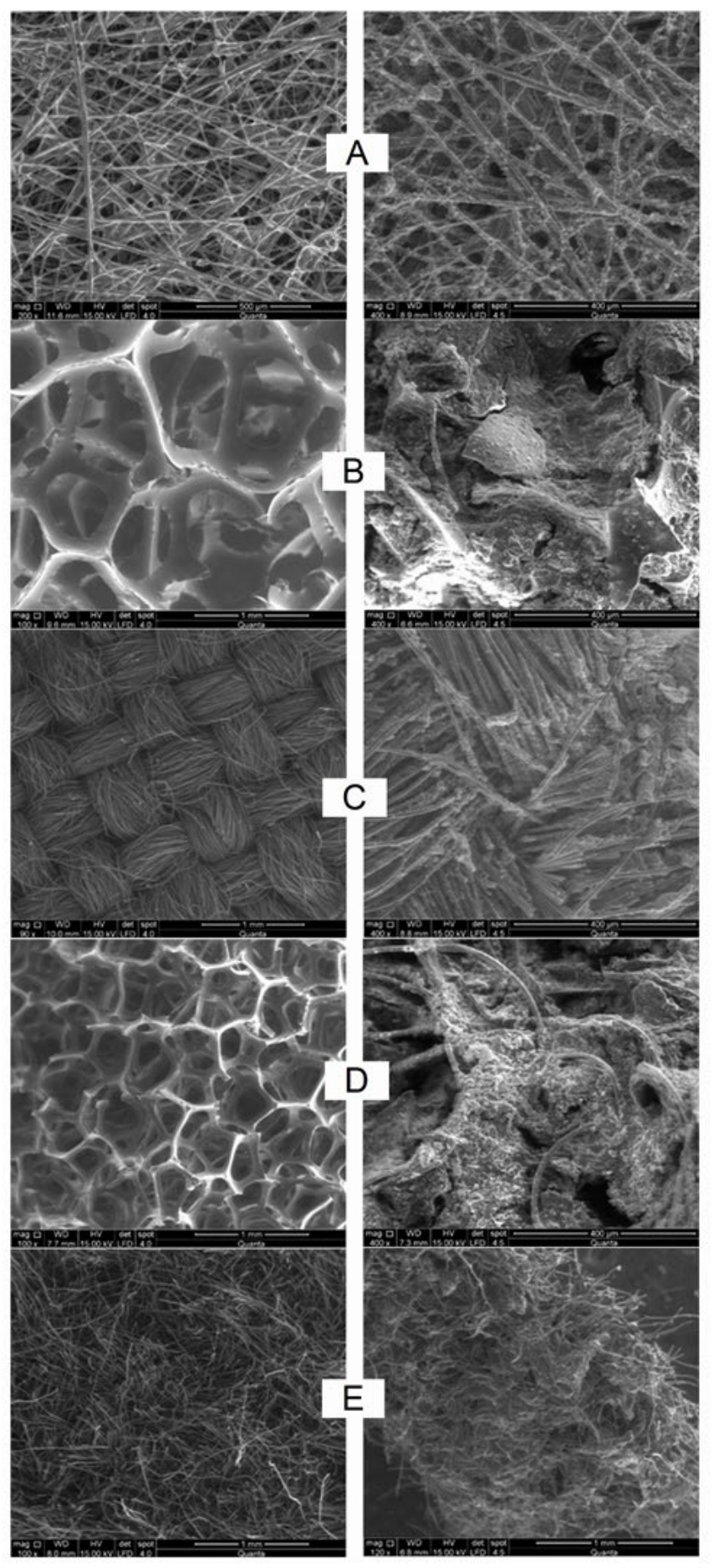

Figure 5. SEM images of the carbonaceous materials before and after the experiments. (A) Carbon paper; (B) Carbon foam of 30 ppi; (C) Carbon cloth; (D) Carbon foam of 80 ppi; (E) Carbon cloth. WD $8.8 \mathrm{~mm}$; HV $15.00 \mathrm{kV}$; det LFD; spot 4.5; quanta $400 \mu \mathrm{m}$. 
According to the results obtained, it can be concluded that porous carbon-based materials enhance its performance mainly due to its higher superficial surface. The surface is used for the development of a biofilm, enriched in Shewanella, what enhances the electron donation capacity. However, limitations appeared when working with carbon materials presenting superficial areas higher than $7500 \mathrm{~m}^{2} \mathrm{~m}^{-2}$. Because of that, the performance or carbonaceous materials with very high porosity is similar in spite of its superficial surfaces. 


\section{Conclusions}

Porous carbonaceous materials showed better performance than plain ones, being the MFC with $\mathrm{CF}$ as anodic electrode material the device that achieves the best performance, exerting 14.5 $\mathrm{A} \mathrm{m}^{-2}$ of current density, $3.99 \mathrm{~W} \mathrm{~m}^{-2}$ of maximum power density and $39.2 \%$ of CE. In general, the higher the superficial surface, the higher current density exerted. However, surfaces over $7500 \mathrm{~m}^{2} \mathrm{~m}^{-2}$ does not increased its performance as expected which could be explained because of microorganisms and mass transfer limitations across the pores. The CE presented a linear relationship with the current density exerted and the superficial surface, indicating a selection of electrogenic microorganisms. The microbial populations were analysed, presenting the biofilm a $14 \%$ of Shewanella whereas its presence was almost negligible in the planktonic culture. Because of that, the main driving force in the carbonaceous materials performance was due to its ability to form biofilm and not to its electronic properties. Because of that the most adequate materials are those presenting up to $7500 \mathrm{~m}^{2} \mathrm{~m}^{-2}$ of specific surface area.

\section{Acknowledgements}

Financial support from the AEI (Agencia Estatal de Investigación) of the Spanish Ministry of Economy and Competitiveness (MINECO) through project CTQ2013-49748-EXP (Explora Program) is gratefully acknowledged. The work of S. Mateo is supported by the Spanish government under a FPU grant (FPU13/04118). 


\section{REFERENCES}

1. Mateo S, Gonzalez del Campo A, Lobato J, Rodrigo M, Cañizares P and Fernandez-Morales FJ, Long-term effects of the transient COD concentration on the performance of microbial fuel cells. Biotechnology Progress 32: 883-890 (2016).

2. Mateo S, Fernandez-Morales FJ, Cañizares $P$ and Rodrigo MA, Influence of the Cathode Platinum Loading and of the Implementation of Membranes on the Performance of AirBreathing Microbial Fuel Cells. Electrocatalysis 8: 442-449 (2017).

3. Janicek A, Fan $\mathrm{Y}$ and Liu $\mathrm{H}$, Design of microbial fuel cells for practical application: a review and analysis of scale-up studies. Biofuels 5: 79-92 (2014).

4. Ledezma P, Greenman J and leropoulos I, MFC-cascade stacks maximise COD reduction and avoid voltage reversal under adverse conditions. Bioresource Technology 134: 158-165 (2013).

5. González Del Campo A, Cañizares P, Lobato J, Rodrigo M and Fernandez Morales FJ, Effects of External Resistance on Microbial Fuel Cell's Performance, in Handbook of Environmental Chemistry, pp. 175-197 (2016).

6. Lobato J, Cañizares P, Fernández FJ and Rodrigo MA, An evaluation of aerobic and anaerobic sludges as start-up material for microbial fuel cell systems. New Biotechnology 29: 415-420 (2012).

7. Vicari F, Mateo S, Fernandez-Morales FJ, Cañizares P, Galia A, Scialdone O and Rodrigo MA, Influence of the methodology of inoculation in the performance of air-breathing microbial fuel cells. Journal of Electroanalytical Chemistry 803: 81-88 (2017).

8. Virdis B, Rabaey K, Yuan Z and Keller J, Microbial fuel cells for simultaneous carbon and nitrogen removal. Water Research 42: 3013-3024 (2008).

9. Gonzalez del Campo A, Lobato J, Cañizares P, Rodrigo MA and Fernandez Morales FJ, Shortterm effects of temperature and COD in a microbial fuel cell. Applied Energy 101: 213-217 (2013).

10. Mateo S, D'Angelo A, Scialdone $\mathrm{O}$, Cañizares $\mathrm{P}$, Rodrigo MA and Fernandez-Morales FJ, The influence of sludge retention time on mixed culture microbial fuel cell start-ups. Biochemical Engineering Journal 123: 38-44 (2017).

11. D'Angelo A, Mateo S, Scialdone O, Cañizares P, Fernandez-Morales FJ and Rodrigo MA, Optimization of the performance of an air-cathode MFC by changing solid retention time. Journal of Chemical Technology and Biotechnology 92: 1746-1755 (2017).

12. leropoulos I, Greenman J and Melhuish C, Improved energy output levels from small-scale Microbial Fuel Cells. Bioelectrochemistry 78: 44-50 (2010).

13. Fan $\mathrm{Y}$, Sharbrough $\mathrm{E}$ and Liu $\mathrm{H}$, Quantification of the Internal Resistance Distribution of Microbial Fuel Cells. Environmental Science \& Technology 42: 8101-8107 (2008).

14. Wang HY, Bernarda A, Huang CY, Lee DJ and Chang JS, Micro-sized microbial fuel cell: A minireview. Bioresource Technology 102: 235-243 (2011).

15. Qian F and Morse DE, Miniaturizing microbial fuel cells. Trends in Biotechnology 29: 62-69 (2011).

16. Ren $\mathrm{H}$, Lee HS and Chae J, Miniaturizing microbial fuel cells for potential portable power sources: Promises and challenges. Microfluidics and Nanofluidics 13: 353-381 (2012). 
17. leropoulos I, Greenman J and Melhuish C, Microbial fuel cells based on carbon veil electrodes: Stack configuration and scalability. International Journal of Energy Research 32: 1228-1240 (2008).

18. Wang $X$, Cheng S, Feng $Y$, Merrill MD, Saito T and Logan BE, Use of carbon mesh anodes and the effect of different pretreatment methods on power production in microbial fuel cells. Environmental Science and Technology 43: 6870-6874 (2009).

19. Wei J, Liang P and Huang X, Recent progress in electrodes for microbial fuel cells. Bioresource Technology 102: 9335-9344 (2011).

20. Kipf E, Koch J, Geiger B, Erben J, Richter K, Gescher J, Zengerle R and Kerzenmacher S, Systematic screening of carbon-based anode materials for microbial fuel cells with Shewanella oneidensis MR-1. Bioresource Technology 146: 386-392 (2013).

21. Shimoyama T, Komukai S, Yamazawa A, Ueno Y, Logan BE and Watanabe K, Electricity generation from model organic wastewater in a cassette-electrode microbial fuel cell. Applied Microbiology and Biotechnology 80: 325-330 (2008).

22. Xie X, Hu L, Pasta M, Wells GF, Kong D, Criddle CS and Cui Y, Three-dimensional carbon nanotube-textile anode for high-performance microbial fuel cells. Nano Letters 11: 291-296 (2011).

23. Tang $\mathrm{Y}, \mathrm{Bi} \mathrm{X}$, Sun $\mathrm{H}$, Fu J, Peng $\mathrm{M}$ and Zou $\mathrm{H}$, Effect of anode with pretreatment on the electricity generation of a single chamber microbial fuel cell, in Advanced Materials Research, pp. 742-746 (2011).

24. Tommasi T, Sacco A, Armato C, Hidalgo D, Millone L, Sanginario A, Tresso E, Schilirò T and Pirri CF, Dynamical analysis of microbial fuel cells based on planar and 3D-packed anodes. Chemical Engineering Journal 288: 38-49 (2016).

25. Mateo S, Rodrigo M, Fonseca LP, Cañizares P and Fernandez-Morales FJ, Oxygen availability effect on the performance of air-breathing cathode microbial fuel cell. Biotechnology Progress (2015).

26. Erbay C, Yang G, De Figueiredo P, Sadr R, Yu C and Han A, Three-dimensional porous carbon nanotube sponges for high-performance anodes of microbial fuel cells. Journal of Power Sources 298: 177-183 (2015).

27. American Public Health Association EADAWWAWEF, Standard methods for the examination of water and wastewater. APHA-AWWA-WEF, Washington, D.C. (2005).

28. Angeles Fernandez de Dios M, Gonzalez del Campo A, Jesus Fernandez F, Rodrigo M, Pazos $M$ and Angeles Sanroman M, Bacterial-fungal interactions enhance power generation in microbial fuel cells and drive dye decolourisation by an ex situ and in situ electro-Fenton process. Bioresource Technology 148: 39-46 (2013).

29. Caporaso JG, Lauber CL, Walters WA, Berg-Lyons D, Huntley J, Fierer N, Owens SM, Betley J, Fraser L, Bauer M, Gormley N, Gilbert JA, Smith G and Knight R, Ultra-high-throughput microbial community analysis on the Illumina HiSeq and MiSeq platforms. The ISME Journal 6: 1621-1624 (2012).

30. Schmieder R and Edwards R, Quality control and preprocessing of metagenomic datasets. Bioinformatics 27: 863-864 (2011).

31. Aronesty E, ea-utils: Command-line tools for processing biological sequencing data. Expression Analysis, Durham, NC (2011).

32. Edgar RC, Haas BJ, Clemente JC, Quince $C$ and Knight R, UCHIME improves sensitivity and speed of chimera detection. Bioinformatics 27: 2194-2200 (2011). 
33. Cole JR, Wang Q, Cardenas E, Fish J, Chai B, Farris RJ, Kulam-Syed-Mohideen AS, McGarrell DM, Marsh T and Garrity GM, The Ribosomal Database Project: improved alignments and new tools for rRNA analysis. Nucleic acids research 37: D141-D145 (2008).

34. Picioreanu C, van Loosdrecht MCM, Curtis TP and Scott K, Model based evaluation of the effect of $\mathrm{pH}$ and electrode geometry on microbial fuel cell performance. Bioelectrochemistry 78: 8-24 (2010).

35. Wei L, Yuan Z, Cui M, Han H and Shen J, Study on electricity-generation characteristic of twochambered microbial fuel cell in continuous flow mode. International Journal of Hydrogen Energy 37: 1067-1073 (2012).

36. Logan BE, Hamelers B, Rozendal R, Schröder U, Keller J, Freguia S, Aelterman P, Verstraete W and Rabaey K, Microbial fuel cells: Methodology and technology. Environmental Science and Technology 40: 5181-5192 (2006).

37. Cheng $\mathrm{S}$, Liu $\mathrm{H}$ and Logan BE, Increased power generation in a continuous flow MFC with advective flow through the porous anode and reduced electrode spacing. Environmental Science and Technology 40: 2426-2432 (2006).

38. Fan $\mathrm{Y}, \mathrm{Hu} \mathrm{H}$ and Liu $\mathrm{H}$, Enhanced Coulombic efficiency and power density of air-cathode microbial fuel cells with an improved cell configuration. Journal of Power Sources 171: 348354 (2007).

39. Cheng $\mathrm{S}$, Liu $\mathrm{H}$ and Logan $\mathrm{BE}$, Increased performance of single-chamber microbial fuel cells using an improved cathode structure. Electrochemistry Communications 8: 489-494 (2006).

40. Mateo S, Zamorano-López N, Borras L, Fernandez-Morales FJ, Cañizares P, Seco A and Rodrigo M, Effect of sludge age on microbial consortia developed in MFCs. Journal of Chemical Technology and Biotechnology.

41. Fernández-Morales FJ, Villaseñor J and Infantes D, Modeling and monitoring of the acclimatization of conventional activated sludge to a biohydrogen producing culture by biokinetic control. International Journal of Hydrogen Energy 35: 10927-10933 (2010).

42. Patel GB and Agnew BJ, Growth and butyric acid production by Clostridium populeti. Archives of Microbiology 150: 267-271 (1988).

43. Lee S, Kim J, Shin SG and Hwang S, Biokinetic parameters and behavior of Aeromonas hydrophila during anaerobic growth. Biotechnology Letters 30: 1011-1016 (2008).

44. Sjöblom M, Matsakas L, Christakopoulos $P$ and Rova $U$, Production of butyric acid by Clostridium tyrobutyricum (ATCC25755) using sweet sorghum stalks and beet molasses. Industrial Crops and Products 74: 535-544 (2015).

45. Zhang $\mathrm{Y}, \mathrm{Ng} \mathrm{CK}$, Cohen $\mathrm{Y}$ and Cao B, Cell growth and protein expression of Shewanella oneidensis in biofilms and hydrogel-entrapped cultures. Molecular BioSystems 10: 10351042 (2014).

46. Risso C, Sun J, Zhuang K, Mahadevan R, DeBoy R, Ismail W, Shrivastava S, Huot H, Kothari S, Daugherty S, Bui O, Schilling $\mathrm{CH}$, Lovley DR and Methé BA, Genome-scale comparison and constraint-based metabolic reconstruction of the facultative anaerobic Fe(III)-reducer Rhodoferax ferrireducens. BMC Genomics 10: 447 (2009).

47. Holmes DE, Giloteaux L, Barlett M, Chavan MA, Smith JA, Williams KH, Wilkins M, Long P and Lovley DR, Molecular analysis of the In situ growth rates of subsurface geobacter species. Applied and Environmental Microbiology 79: 1646-1653 (2013). 
